\title{
Characterization of a Germline Vk Gene Encoding Cationic Anti-DNA Antibody and Role of Receptor Editing for Development of the Autoantibody in Patients with Systemic Lupus Erythematosus
}

\author{
Noboru Suzuki, Tatsuhiro Harada, Shoji Mihara, and Tsuyoshi Sakane \\ Division of Allergy and Rheumatic Diseases, Institute of Medical Science, St. Marianna University School of Medicine, Kawasaki, \\ Kanagawa 216, Japan
}

\begin{abstract}
We found previously that cationic anti-DNA autoantibodies (autoAbs) have nephritogenic potential and usage of a specific germline Vk gene, A30, has major influences on cationic charge of the autoAb in human lupus nephritis. In the present study, we have characterized A30 germline Vk gene using cosmid cloning technique in patients with SLE. A30 gene locus locates in less than $250 \mathrm{~kb}$ from the $\mathrm{Ck}$ region, and the cationic anti-DNA mRNA used the upstream Jk2 gene, indicating that cationic anti-DNA mRNA is a product of primary gene rearrangement. By using PCR technique, we found that $\mathrm{A} 30$ gene locus in the genome was defective in eight out of nine SLE patients without nephritis. In contrast, all nine patients with lupus nephritis had intact A30 gene. The presence and absence of $\mathrm{A} 30$ gene was associated with the development of lupus nephritis or not $(P<0.01$, by Fisher's exact test, two-sided). It was thus suggested that absence of functional A30 gene may rescue from developing lupus nephritis in the patients. A30 is reported to be a potentially functional but rarely expressed Vk gene in humans. It is possible that normal B cells edit primarily rearranged $\mathrm{A} 30$ gene with autoreactive potentials by receptor editing mechanism for changing the affinity of the $\mathrm{B}$ cell $\mathrm{Ag}$ receptor to avoid self-reactivity, whereas SLE B cells may have a defect in this mechanism. Indeed, we found that normal B cells edit A30-Jk2 gene in their genome possibly by inversion mechanism, whereas SLE B cells contain rearranged A30-Jk2-Ck gene in the genome and express A30-associated mRNA, suggesting that receptor editing mechanism is also defective in patients with SLE. Our study suggests that polymorphism of Ig Vk locus, and failure of receptor editing may contribute to the development of pathogenic anti-DNA responses in humans. (J. Clin. Invest. 1996. 98:1843-1850.) Key words: polymorphism $\bullet$ primary rearrangement $\bullet$ lupus nephritis $\bullet$ self reactivity $\bullet$ A30 gene
\end{abstract}

\footnotetext{
Address correspondence to Dr. Tsuyoshi Sakane, M.D., Division of Allergy and Rheumatic Diseases, Institute of Medical Science, St. Marianna University School of Medicine, 2-16-1, Sugao, Miyakmaeku, Kawasaki, Kanagawa, 216, Japan. Phone: 81-44-977-8111; FAX: 81-44-975-4347.

Received for publication 11 January 1996 and accepted in revised form 8 August 1996.
}

J. Clin. Invest.

(C) The American Society for Clinical Investigation, Inc. 0021-9738/96/10/1843/08 \$2.00

Volume 98, Number 8, October 1996, 1843-1850

\section{Introduction}

The appearance of anti-DNA antibodies $(\mathrm{Abs})^{1}$ in circulation represents the disease activity of systemic lupus erythematosus (SLE) and anti-DNA Abs by themselves and/or their immune complexes are intimately associated with the pathogenesis (1-5). We have recently found that cationic anti-DNA Abs play major roles in the development of human lupus nephritis $(6,7)$. In an attempt to clarify the molecular basis for the production of such Abs in patients with lupus nephritis, we found that the germline Ig Vk gene of the human cationic anti-DNA Ab is A30 gene designated by Zachau, which encodes extraordinary cationic Ab protein (8) having positively charged amino acids in the complementary determining regions.

The $\mathrm{k}$ locus of human Ig V gene contains approximately 70 genes and locates on the short arm of chromosome 2 at 2p112q-12 (9). Moreover, it is reported that there are at least 16 polymorphisms and 9 haplotypes in the Vk cluster of normal individuals (10). It has been reported that certain polymorphisms within the human Ig Vk locus are associated with rheumatoid arthritis $(11,12)$. In addition, it has been shown that polymorphisms in the two human $\mathrm{VH}$ genes, both of which can encode anti-DNA Abs are related with the development of autoimmune diseases (13-15). Other study has also suggested that $\mathrm{VH}$ haplotypes may have linkage with auto $\mathrm{Ab}$ production (16). To date, none of the polymorphisms and haplotypes of the Vk cluster are reported to be associated with SLE (17).

To investigate the molecular basis for the development of cationic anti-DNA Ab precisely, we have performed cloning of a cosmid library constructed with genomic DNA of a patient with severe lupus nephritis. (Nucleotide sequences of the clones we have identified are currently applying for the GenBank/EMBL/DDBJ accession numbers.) We have succeeded in isolating a cosmid clone including a germline Ig Vk gene that is associated with cationic anti-DNA Ab, and we have conducted a characterization of this gene locus. In addition, we have addressed whether failure of receptor editing of the $\mathrm{Vk}$ gene with autoreactive potential is associated with the development of anti-DNA Ab in patients with SLE. Our present study strongly suggests that genetic predisposition and failure of receptor editing are intimately associated with the development of anti-DNA $\mathrm{Ab}$ in patients with SLE.

\section{Methods}

Patients. We studied 18 patients, all women, who fulfilled the 1982 revised criteria for the classification of SLE by American Rheuma-

1. Abbreviations used in this paper: $\mathrm{Ab}, \mathrm{Abs}$, antibodies; $\mathrm{DIG}$, digoxigenin; SLE, systemic lupus erythematosus. 
tism Association (18). The mean age $( \pm \mathrm{SD})$ of these patients was $35.1 \pm 9.2 \mathrm{yr}$ (range 14-55). Active lupus nephritis was defined as persistent proteinuria of more than $2 \mathrm{~g} / \mathrm{d}$ with positive cellular casts and/ or microscopic hematuria. Patients who lack proteinuria, cellular casts, and microscopic hematuria were categorized as having inactive renal disease $(6,8)$. The Human Studies Committee's approval and individual informed consent from each patient were obtained before we conducted the present study. 29 healthy female volunteer blood donors served as control subjects. Their mean age $( \pm \mathrm{SD})$ was $36.2 \pm 6.3$ yr (range 25-52).

Preparation of human genomic DNA. High molecular weight genomic DNA was obtained from purified neutrophils of the patients and normal individuals, using a standard method (19). Briefly, purified neutrophils were prepared from buffy coat fraction by removal of lymphocytes using a Ficoll-Hypaque density gradient centrifugation, and resulting neutrophil fraction contained $<0.1 \%$ of contaminating B cells, which react with anti-CD20 mAb (Leu 16; Becton Dickinson Monoclonal Center, Inc., Mountain View, CA) when analyzed by flow cytometry (8). B cells were purified by means of a SRBC rosette technique, followed by depletion of monocytes by a Petri dish adherence procedure. B cells were further purified by panning with anti-CD3 (OKT3; Ortho Diagnostic Systems, Inc., Raritan, NJ) and anti-CD14 and CD56 mAbs (LeuM3 and Leu19; Becton Dickinson Monoclonal Center) (20). Purified human neutrophils and B lymphocytes were digested with proteinase $\mathrm{K}$ and pancreatic ribonuclease in the presence of EDTA and SDS, followed by extraction with phenol. Low molecular weight contaminants were removed by dialysis.

Construction of cosmid library of genomic DNA of neutrophils from a patient with severe lupus nephritis. Genomic DNA library of neutrophils from patient $S$ with severe lupus nephritis was constructed using SuperCos1 cosmid vector and Gigapack II packaging extract (Stratagene, Inc., La Jolla, CA), as suggested by the manufacturer. Efficiencies of $1.8 \times 10^{5}$ to $2.5 \times 10^{5}$ cosmid clones $/ \mu \mathrm{g}$ inserted DNA were obtained.

Screening was performed against $7 \times 10^{5}$ colonies, which covered more than $99.9 \%$ of the human genome (19), with digoxigenin (DIG; Boehringer Mannheim Biochemica, Mannheim, Germany) labeled A30 (8) probe under stringent washing conditions. DNA sequencing was performed by a dideoxy method using Sequenase version 2.0 kit (United States Biochemical Corp., Cleveland, OH).
Restriction maps. Restriction maps of the cosmid clone were constructed using established procedures (21). In brief, the inserted DNA that has cleaved by NotI restriction nuclease carried T3 or T7 promoter sequences at either the $5^{\prime}$ end or the $3^{\prime}$ end, derived from the cosmid vector. Partially digested and completely digested insert DNA with different restriction nucleases were separated on $0.4 \%$ (wt/vol) agarose gel and transferred to positive charged nylon membrane. Filters were hybridized with $3^{\prime}$ end DIG-labeled T3 or T7 oligonucleotide probe and then detected by chemiluminescent detection kit (Boehringer Mannheim Biochemica).

Computer-aided sequence comparison. The DNASIS software (Hitachi Software Engineering Co., Ltd., Tokyo) was used with GenBank and EMBL databases.

Primers and probes used in this study. Sequences and positions of oligonucleotide primers and oligonucleotide probes were shown in Fig. 1 and Table I. Up1 primer is designed to hybridize to the upstream region of A30 gene and this sequence exists just upon the breakpoint of the germline Ig Vk Ap region (Fig. 1, arrowhead). The primer termed g87 is an antisense oligonucleotide of the gs 87 oligonucleotide, which is the specific sequence for A30. The primer termed A30-3' AS is designed to distinguish A30 from L11 gene (22), which is quite similar (96.5\% homology) with A30 gene. m659-2, which was isolated from the downstream region of A29 germline gene, was kindly provided by Prof. H.G. Zachau (University of Munich, Munich, Germany) (23). m659-2 is one of the duplication differentiating polymorphism, DDP, probe of the proximal A region of human Ig Vk locus (10).

For detection probes, we used 3' end DIG-labeled c-1-1 probe, g87 probe and A30-3'AS probe. A XbaI/HindIII fragment of Scos 10 clone including A30 gene (termed Scos10-f2) and m659-2 were DIG labeled using Nick translation kit (Boehringer Mannheim Biochemica).

Cloning of A30 locus from the genome of a normal individual. To clarify whether there is any difference of A30 gene organization between a SLE patient and a normal individual, we have cloned a normal counterpart by PCR using genomic DNA of a normal individual (WK). To amplify the upstream region of A30, PCR was performed between Up0 primer and g87 primer (see Fig. 1 and Table I). Similarly, downstream region of A30 was amplified using gs87 primer and Down1 primer. The PCR products of the expected size were recovered and ligated into the pCR-Script ${ }^{\mathrm{TM}} \mathrm{SK}(+)$ vector

A

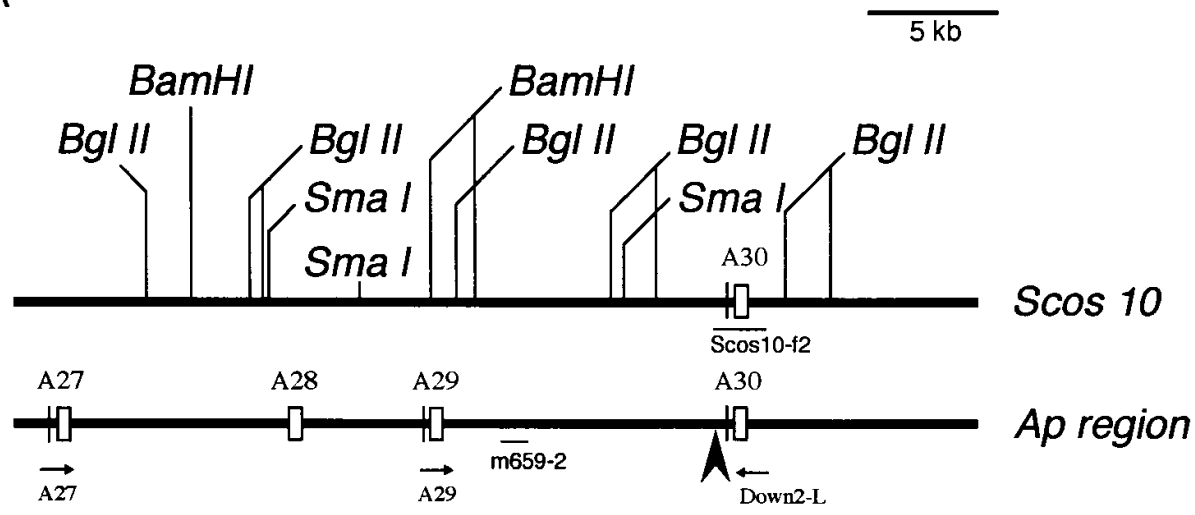

Figure 1. Restriction maps of Scos 10 and position of primers and probes used in this study. $(A) \mathrm{Re}-$ striction maps of Scos 10 and position of long oligonucleotide primers used for long distance PCR study. Scos 10 was mapped by restriction endonucleases including BamHI, BglII, and SmaI. Proximal A region of human Ig Vk locus, essentially the same with $S \cos 10$, was presented for comparison (23). Scos 10-f2 was a XbaI/HindIII fragment of Scos 10 containing A30 gene, and its nucleotide sequence was deter-

B

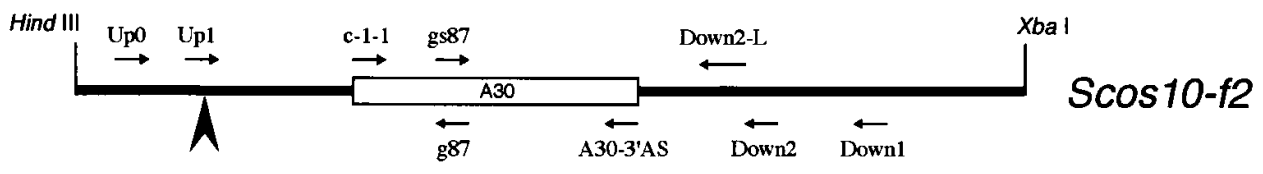
mined after subcloning into pBluescript II vector. $(B)$ Schematic representation of Scos 10-f2. Position of primers used in this study was also presented. Arrowheads in $A$ and $B$ represent a breakpoint reported by Lautner-Rieske et al. (23). 


\begin{tabular}{|c|c|}
\hline \multicolumn{2}{|c|}{ Primers used for short PCR } \\
\hline Up0 & 5'-ATGTTAAATATAGGCCCC-3' \\
\hline $\mathrm{Up} 1$ & 5' - CTCTCTAGCTGCATATAC- - 3' \\
\hline g87 & 5' - TACCAGCCTAAATCATTTCTA - 3' \\
\hline gs87 & 5' - TAGAAATGATTTAGGCTGGTA - 3' \\
\hline Down 2 & 5' - ACTTCTGAGATAACTTGA - 3' \\
\hline Down 1 & 5' - TGAATCAGGACAGTGGGA - 3' \\
\hline Jk1 & 5' - CCCTTGGCCGAACGTCCA - 3' \\
\hline $\mathrm{Jk} 2$ & 5' - CCCCTGGCCAAAAGTGTA - 3' \\
\hline $\mathrm{Jk} 3$ & 5' - ATCCACTTTGGTCCCAGG - 3' \\
\hline $\mathrm{Jk} 4$ & $5^{\prime}-$ CCCTCCGCCAAAGTGAG - 3' \\
\hline Jk5 short & 5' - TTTAATCTCCAGTCGTGT- 3' \\
\hline \multicolumn{2}{|c|}{ Oligonucleotide probes used for the detection of A30 specific PCR products } \\
\hline $\mathrm{c}-1-1$ & 5' - GCTCTAGAAGCCATCCAGATGACCCAG - 3' \\
\hline A30-3'AS & 5' - AGGGTAACTATTATGCTG - 3' \\
\hline g87 & 5' - TACCAGCCTAAATCATTTCTA - 3' \\
\hline gs87 & 5' - TAGAAATGATTTAGGCTGGTA - 3' \\
\hline \multicolumn{2}{|c|}{ Primers used for long PCR } \\
\hline A27 & 5' - CAATGCCTGGGTCAGAGCTCTGGAGAAGAG - 3' \\
\hline A29 & 5' - AGCTCCTGATTTATAGGGTTTCCAATCATC - 3' \\
\hline A30 sense & $5^{\prime}$ - GACATCCAGATGACCCCAGTCTCCATCCTCC - 3 \\
\hline Down2-L & $5^{\prime}$ - CTTTGTCCACCACTGCTTCCCAGTCTGAGC - 3' \\
\hline $\mathrm{Ck}+20$ & 5' - AACTGCTCATCAGATGGCGGGAAGATGAAG - 3' \\
\hline $\mathrm{Jk} 5$ long & 5' - ACGTTTAATCTCCAGTCGTGTCCCTTGG - 3' \\
\hline
\end{tabular}

c-1-1 primer was designed in the previous report (8) and nucleotides with underline represented a XbaI cutting site. Down2 primer and Down2-L primer were designed to hybridize with neighboring but not identical position.

(Stratagene Inc.). The clone of upstream region (gs87 primer and Down1 primer) was termed WKU0G1 and that of downstream region was WK87D1-40.

Detection by PCR of A30 gene deletion in patients with SLE and normal individuals. To clarify whether functional A30 gene is present or deleted within the genomic DNA of normal individuals and patients with SLE, PCR was carried out. PCR primers were designed to amplify a 863-bp fragment of the A30 upstream region, spanning -755 to +107 relative to the $\mathrm{A} 30 \mathrm{Vk}$ coding region start site, and a 837-bp fragment of the downstream region spanning +87 to +750 . In addition A30 coding region was also amplified. $10 \mathrm{ng}$ genomic DNA was PCR amplified as follows: 50 cycles at $94^{\circ} \mathrm{C}$ for 1 $\min , 55^{\circ} \mathrm{C}$ for $2 \mathrm{~min}, 72^{\circ} \mathrm{C}$ for $2 \mathrm{~min}$, and then a final $10 \mathrm{~min}$ at $72^{\circ} \mathrm{C}$. The PCR products were hybridized to the probes listed in Table I to confirm their identity.

Long distance PCR of human genomic DNA. Long distance PCR $(24,25)$ was performed using LA PCR kit (Takara Biochem, Inc., Kyoto, Japan), with a set of long oligonucleotides described in Fig. 1 and Table I. The A29 primer was designed to distinguish A29 Vk gene (23) from A13 Vk gene (23), which is reported to be a duplicated copy of the A29 gene. $100 \mathrm{ng}$ of genomic DNA of the neutrophils or purified B cells was added to $50 \mu \mathrm{l}$ reaction mixture of the kit and amplified as follows: 35 cycles at $98^{\circ} \mathrm{C}$ for $20 \mathrm{~s}, 68^{\circ} \mathrm{C}$ for $15 \mathrm{~min}$, after $2 \mathrm{~min}$ at $94^{\circ} \mathrm{C}$, and then a final $10 \mathrm{~min}$ at $72^{\circ} \mathrm{C}$. The PCR products were hybridized to the probes mentioned in Fig. 1 to confirm their identity. In some experiments, long distance PCR products were purified by glass bead methods. Using the purified product or the B cell genomic DNA as a template, conventional PCR was carried out with a combination of A30 sense primer and Jk2 antisense primer. Resulting products were further nested amplified by PCR using g87 primer and $\mathrm{Jk} 2$ antisense primer, and their sequences directly determined as has been reported (26).

\section{Results}

Isolation and restriction mapping of the cosmid clone. We have previously characterized coding region of a germline $\mathrm{Ig} \mathrm{Vk}$ gene encoding cationic anti-DNA $\mathrm{Ab} \mathrm{L}$ chain obtained by PCR reaction of the genomic DNA from the patient's neutrophils (8) and the germline Ig Vk gene was found to be identical with A30 gene designated by Zachau. In this study, we have obtained a cosmid clone that contained A30 gene, termed Scos 10 , in an attempt to clarify the difference of Ig Vk gene locus between SLE patients and normal individuals.

Scos 10 had $36.5 \mathrm{~kb}$ inserted DNA. The restriction maps of BglII, BamHI, and SmaI on the Scos 10 clone were shown in the Fig. $1 \mathrm{~A}$. Compared with the human Vk locus previously reported by Zachau and co-workers (23), restriction maps of our Scos 10 were essentially the same with the Ap proximal region containing A27, A28, A29, and A30 genes.

To characterize A30 gene of the SLE patient precisely, Scos 10 was digested by XbaI and HindIII, which do not cleave A30 gene coding region. The positive fragment that hybridizes with A30 probe, about $2.3 \mathrm{~kb}$ in length (termed Scos 10-f2), was subcloned into pBluescript II, and the nucleotide sequence determined (Fig. 2). This fragment included single Vk gene and the sequence of the coding region was entirely matched with the A30 sequence except one base that locates within the 5 ' primer (c-1-1) portion of the A30 Vk gene used in the previous report (8) and the sequence of this $\mathrm{Vk}$ gene was completely matched with A30 gene reported by Zachau (23). The nucleotide sequence of the upstream region of this frag- 
A

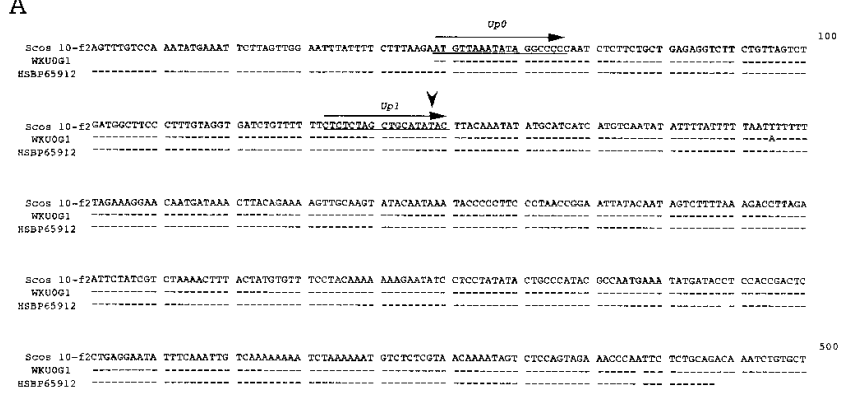

B

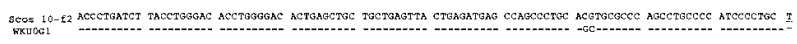

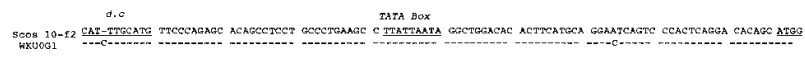

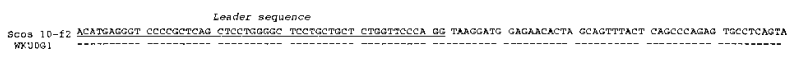

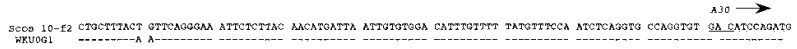

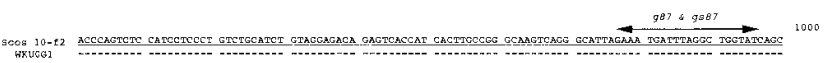
кхв $72 \mathrm{D}-$-40

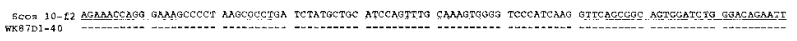

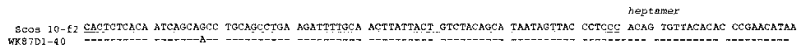

$\mathrm{C}$

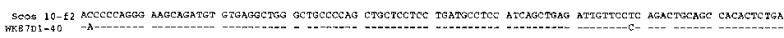

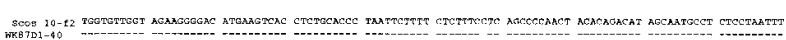

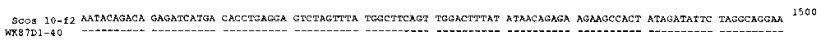

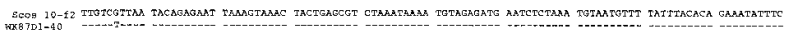

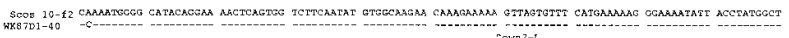

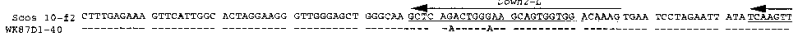

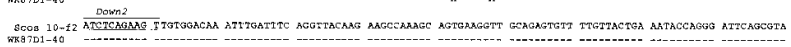

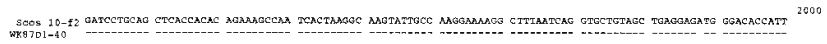

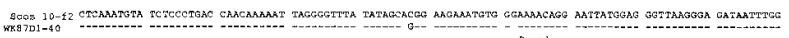

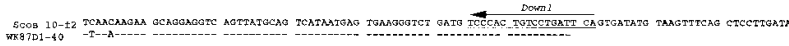

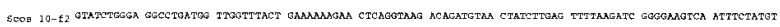

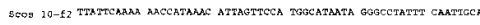

Figure 2. Nucleotide sequence of Scos 10-f2, A30 gene of a normal individual and HSBP65912. The nucleotide sequences of XbaI/HindIII fragment of Scos 10 including A30 (Scos 10-f2), HSBP65912, WKU0G1, and WK87D1-40 were compared. WKU0G1 was derived from the upstream region of A30 locus by PCR of genomic DNA from a normal individual (WK) and WK87D1 was from the downstream region. The arrowhead represents a breakpoint reported by Lautner-Rieske et al. (23). Primer position used in conventional PCR study and Down2-L primer used in the long distance PCR were indicated. $(A)$ The upstream region of $\mathrm{A} 30$ gene, $(B) \mathrm{A} 30 \mathrm{Vk}$ germline gene coding region, and $(C)$ the downstream region of $\mathrm{A} 30$ gene.

ment was the same with the sequence of HSBP65912 (23) deposited in the GenBank database, which included a breakpoint sequence with $L I N E$ homology region corresponding to the upstream of A30 Vk gene $(23,27)$. Thus, we have determined the germline Ig Vk gene, corresponding to the cationic anti-DNA $\mathrm{Ab} \mathrm{L}$ chain mRNA that has been shown to play major roles in the development of lupus nephritis (6-8), is A30 gene. In addition, we found that there were no structural abnormalities such as heptamer-nonamer sequences and a promoter region (see below), suggesting that A30 is potentially functional in patients with SLE. The finding that A30 is potentially functional in normal individuals has already been reported by Zachau (27).
Nucleotide sequences of A30 germline Vk gene locus in a patient with SLE and a normal individual. We have compared whether there is any difference of A30 germline Vk gene locus between a patient with SLE and a normal individual by PCR. To study the entire A30 gene locus that spans about $2.4 \mathrm{~kb}$ efficiently, we have synthesized three sets of PCR primers. The PCR products that correspond to upstream region of A30 gene, A30 germline $\mathrm{Vk}$ gene coding region, and downstream region of A30 gene were obtained and their sequences determined (Fig. $2, A-C)$. The sequence of A30 locus of the normal individual (WK), especially the $5^{\prime}$ untranslated region (Fig. $2 B$ ) and the downstream region (Fig. $2 C$ ), was somewhat different from that of the SLE patient. However essential sequences such as TATA box, leader sequence, coding region, and heptamer sequence were the same with that of the SLE patient. In addition, there was no major/minor alteration of A30 coding region (Fig. $2 B$ ) and the upstream region (Fig. $2 A$ ) between a patient with lupus nephritis and a normal individual. Nonetheless, whether the minor differences of these sequences may affect the transcription efficiency is needed to be studied.

Polymorphisms in A30 locus of the patient's genome. In the previous study, we have reported that the cationic anti-DNA $\mathrm{Ab} \mathrm{L}$ chain mRNA expression is restricted to patients with lupus nephritis (8). Thus, it is important to study whether there is
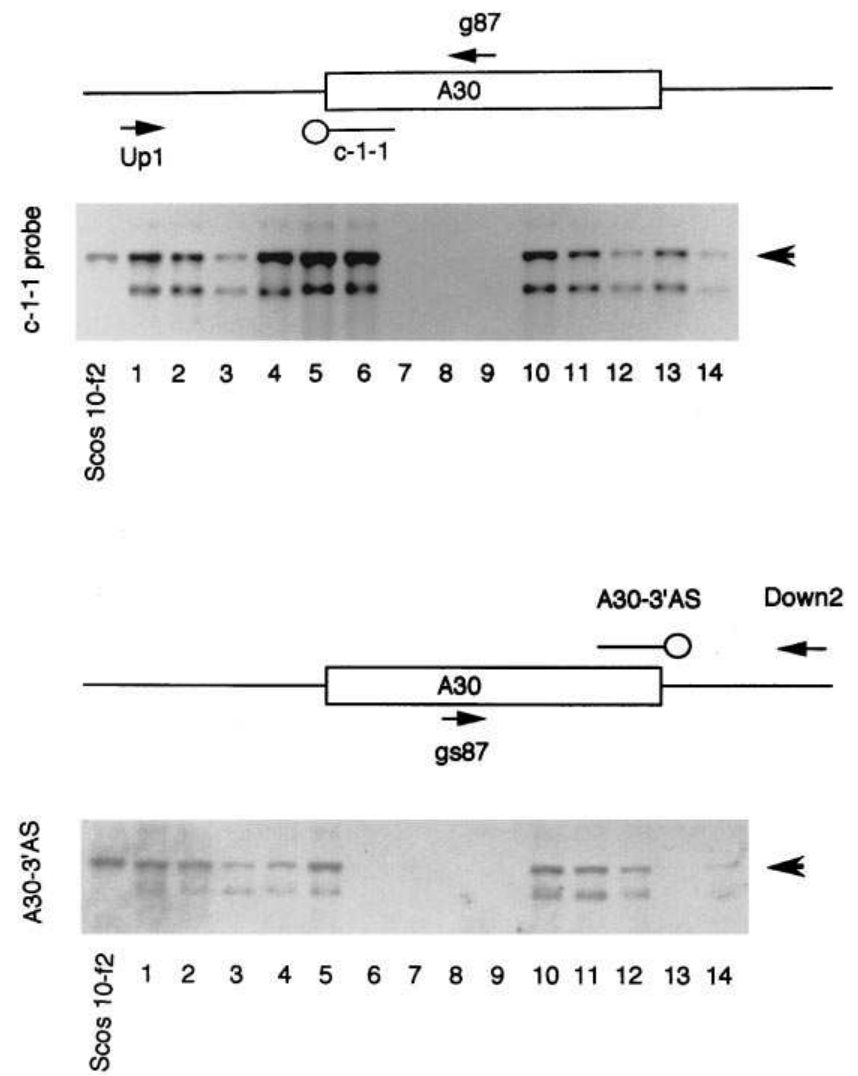

Figure 3. Characterization of A30 locus in patients with SLE. For amplification of the upstream region of A30 gene from human genomic DNA, Up1 primer and g87 primer were used, followed by hybridization with c-1-1 probe. Similarly, for the downstream of A30, PCR products between gs 87 primer and Down 2 primer were hybridized to A30-3' AS probe. As a control template, Scos 10-f2 was used. Lanes 1-5, patients with nephritis; lanes 6-9, patients without nephritis; lanes $10-14$, normal individuals. 
any difference in the organization of germline A30 gene between normal individuals and lupus patients with/without nephritis. From the nucleotide sequences of the SLE patient and the normal individual (Fig. 2), we have synthesized oligonucleotide primers shown in Fig. $1 B$ and Table I. We have conducted PCR and subsequent hybridization study of genomic DNA from SLE patients with/without nephritis and normal individuals. Results of five normal individuals, five patients with lupus nephritis, and four patients without nephritis are shown in Fig. 3.

We made two sets of PCR primers for amplification of A30 locus. To amplify A30 upstream region (Fig. 3, top), PCR was carried out using primer Up1, which corresponds to the break point in the upstream region of A30 gene, and primer g87, which hybridizes to the specific sequence of A30, followed by hybridization to c-1-1 probe, $5^{\prime}$ portion of A30 coding region. In addition, the downstream region of A30 gene was PCR amplified using gs 87 primer, antisense of g87, and Down2 primer, $\sim 0.9 \mathrm{~kb}$ downstream from the $\mathrm{A} 30 \mathrm{Vk}$ coding region start site, and hybridized with A30-3' AS probe, $3^{\prime}$ portion of A30 coding region (Fig. 3, bottom).

To date, we have tested 29 normal donors, 9 patients with lupus nephritis, and 9 patients without nephritis. We interpreted the results as follows: if a patient has a functional A30 gene, then the upstream region, A30 coding region, and the downstream region should all be amplified. In patients without nephritis, only one patient had both upstream and downstream PCR products in the nine patients tested, suggesting that only one patient had intact A30 gene locus and that a vast majority of the patients lacked a functional A30 gene. In contrast, in patients with nephritis, nine patients tested had both PCR products suggesting that all the patients tested had functional A30 gene. In 29 normal individuals tested, 22 had both PCR products, the remaining $7 \mathrm{did}$ not. Thus, the existence and integrity of A30 gene in the genome was significantly different between the patients with nephritis and those without nephritis by Fisher's exact test (two-sided; $P<0.01$ ). These results further suggest that the patients without nephritis may have some defects within A30 gene locus, which encodes the cationic and thus pathogenic anti-DNA Ab L chain V region. Thus, the patients would lack cationic anti-DNA $\mathrm{Ab}$ in their circulation, leading to rescue of the patients from development of renal manifestation of SLE.

Defects in the germline Ig Vk gene of SLE patients without nephritis shown by long distance PCR. A30 germline Vk gene has been reported to have a breakpoint on the 0.8 -kb upstream of coding region, at which genetic deletion or transposition could occur during evolution (23). Because A30 locus of patients without nephritis was found to be defective by conventional PCR, we have further confirmed the above finding by performing long distance PCR. We made A29 primer (the upstream of A29 gene) and Down2-L primer (the downstream of A30 gene) to yield a $13.5-\mathrm{kb}$ PCR fragment corresponding to the $3^{\prime}$ end of Ap region. A $13.5-\mathrm{kb}$ amplified product should be amplified if the integrity of A30 locus in patients without nephritis is not compromised. Fig. 4 shows representative results of the experiments. In summary, 22 out of 29 normal individuals tested and all nine patients with nephritis had the 13.5kb-long distance PCR products. 7 out of 29 normal individuals lacked the 13.5 -kb product. Eight out of nine patients without nephritis having defects within A30 region of their genomic DNA by conventional PCR (see Fig. 3) lacked the $13.5-\mathrm{kb}$ product. Only one out of nine patients without nephritis had the $13.5 \mathrm{~kb}$ product. Thus, the results of long distance PCR experiments were essentially the same with the conventional PCR experiments. Statistical data analysis of the long distance PCR experiments confirmed that the existence and integrity of A30 gene in the genome was significantly different between the patients with nephritis and those without nephritis by Fisher's exact test (two-sided; $P<0.01$ ).

Receptor editing of autoreactive Ig receptor by $B$ cells in normal subjects and in patients with SLE. Because there is no major structural difference of A30 gene locus between normal individuals and patients with lupus nephritis, it is important to clarify whether other mechanisms than genomic organization of the Ig Vk locus have some influences on the development of auto $\mathrm{Ab}$ in humans. To this end, we take advantage of our assumption that A30 may be autoAg-associated Ig Vk gene, because the cationic anti-DNA Ab used the A30-Jk2-Ck gene with somatic mutations ( 8,27 ; see Discussion).

It is possible that the A30 gene may be once productively rearranged and be expressed on the cell surface of immature $\mathrm{B}$ cells in the bone marrow. The rearranged A30 gene products of the B cells would react with autoAg, thereafter in normal individuals, receptor editing mechanisms would operate, leading to the secondary gene rearrangement using the combination of upstream $\mathrm{Vk}$ gene and downstream $\mathrm{Jk}$ gene via inversion or other mechanisms by upregulation of recombination activating genes $(28,29)$. If secondary gene rearrangement would take place by inversion mechanism, productively rearranged germline A30-Jk2 gene might be present far distant from $\mathrm{Ck}$ gene with reverse orientation in the normal B cell genome. Using conventional and long distance PCR of genomic DNA from purified B cells, we found that A30-Jk2 $(\sim 300 \mathrm{bp})$ fragment was successfully amplified in normal individuals. On the other hand, A30-Ck $(\sim 6 \mathrm{~kb})$ fragment was not amplified in the B cell genomic DNA from all the normal individuals tested. In striking contrast, both the A30-Jk2 fragment and A30-Ck (including Jk2; see legend for Fig. 5) fragment were amplified in the B cell genome of patients with SLE. There were no A30Jk2 fragment and A30-Ck fragment amplified in SLE patient 5 who lacked A30 gene in her genome (Fig. 5). Thus it is suggested that rearranged germline A30-Jk2 gene is really present
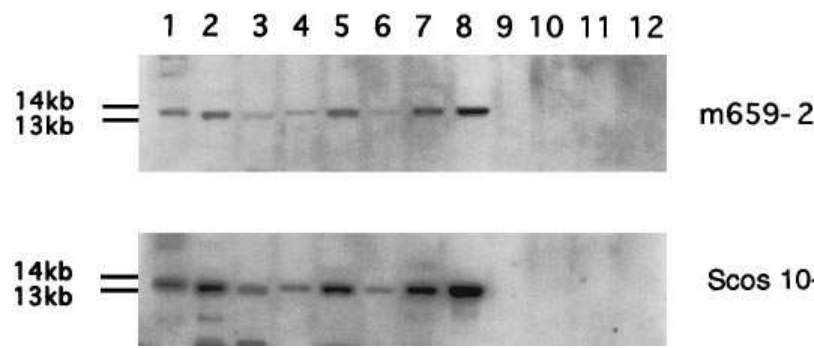

$\mathrm{S} \cos 10-\mathrm{f} 2$

Figure 4. Long distance PCR in Ap region of the genome from patients with/without nephritis. Long distance PCR between A29 primer and Down2-L and subsequent hybridization study were performed. Long distance PCR products from normal individuals (lanes 1-4), patients with lupus nephritis (lanes 5-8) and lupus patients without nephritis (lanes 9-12) were loaded on a $0.6 \%$ agarose gel and hybridized with m659-2 probe, which was isolated from the downstream region of A29 germline gene by Pargent (10) (see Fig. $1 A$ ). The blot was also hybridized with Scos 10-f2 probe containing A30 gene. The size of the amplified products are $\sim 13.5 \mathrm{~kb}$. 

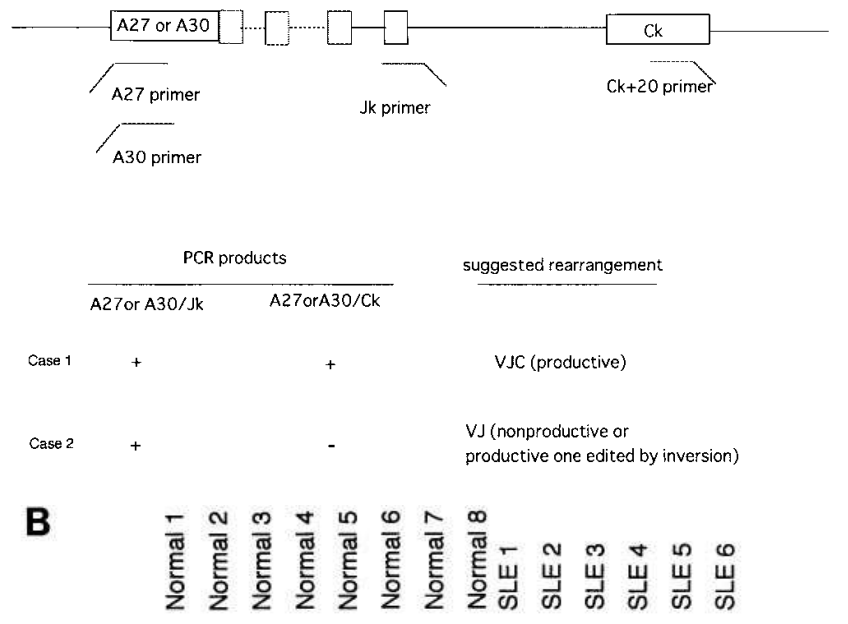

A27-Ck

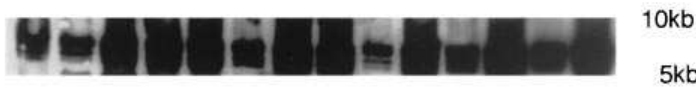

$\mathrm{A} 30-\mathrm{Ck}$

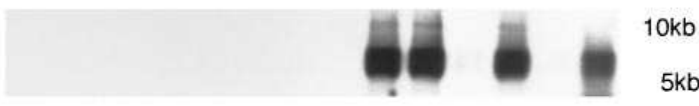

A30-Jk2

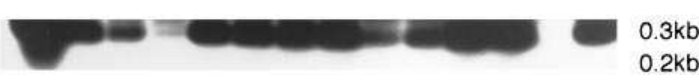

Figure 5. Rearrangement pattern of A30 Jk2 Ck segments in B cell genomic DNA in patients with SLE. ( $A$ ) Schematic representation of long distance PCR for detecting receptor editing in B cells. $(B)$ Results of long distance PCR detecting receptor editing in B cells. Long distance PCR between A27 primer or A30 primer and $\mathrm{Ck}+20$ primer ( $\sim 6 \mathrm{~kb}$ ) was carried out to study whether A27-Ck and A30-Ck rearranged products were present within the B cell genomic DNA. Long distance PCR products from genomic DNA of purified B cells in patients with SLE were loaded on a $0.8 \%$ agarose gel and subsequently hybridized with A27 probe or g-87 probe that is specific for A30. Similarly conventional PCR using A30 primer and Jk2 primer ( $\sim 300 \mathrm{bp}$ ) was carried out to analyze whether A30-Jk2 rearranged products are present in the B cell genomic DNA, followed by hybridization with g- 87 probe. Conventional PCR with $\mathrm{A} 30$ primer and $\mathrm{Jk} 2$ primer was also conducted using purified long distance PCR products of SLE B cells as templates, and we confirmed that $\mathrm{A} 30-\mathrm{Jk} 2-\mathrm{Ck}$ was really rearranged in the SLE B cells (data not shown). Patients 1, 2, 3, 4, and 6 had renal diseases, whereas patient 5 lacked renal manifestation.

in the B cell genome far distant from Ck gene with possibly reverse orientation in normal individuals, even though we do not know the exact orientation. Thus, it should be emphasized that A30 is edited in normal B cells, whereas SLE B cells do not edit and express A30-derived mRNA and Ab, as has been reported (8).

As a normal control of autoreactive A30 gene we choose A27 gene, a Vk gene that is also functionally competent Vk gene and is expressed very frequently in normal individuals (27). Both A27-Jk2 and A27-Jk2-Ck are consistently amplified in the B cell genomic DNA of normal individuals as well as of patients with SLE. Thus at least some A27 genes are not receptor edited in the B cell genome in normal individuals and in patients with SLE.

It is important to confirm that A30-Jk2 fragments of normal $\mathrm{B}$ cells are productively rearranged, because A30-Jk2-derived Ig should be expressed at immature/mature B cells before receptor editing takes place. To this end, we have first amplified A30-Jk2 fragments by PCR using purified B cell genomic DNA as templates. The products were gel purified and were used as templates for second PCR using g87 primer and Jk2 primer. Sequencing of the fragments from three normal individuals revealed that they were productive, and some of them were identical with cationic anti-DNA Ab light chain cDNA. Thus, it is suggested that A30-Jk2 gene that is once productively rearranged may be receptor edited in normal B cells.

\section{Discussion}

Many investigators have recently characterized potentially pathogenic, disease-associated anti-DNA Abs in both humans and mice in an attempt to determine the mechanisms leading to production of the pathogenic autoAbs $(30,31)$. We have previously reported close relationship between the presence of cationic anti-DNA Abs and the development of lupus nephritis in humans $(6,7)$. In addition, it has been suggested that usage of certain germline gene is important for the development of cationic anti-DNA Ab, while somatic mutations are associated with affinity maturation of anti-DNA $\mathrm{Ab}$ in human lupus nephritis, and that mRNA expression of cationic anti-DNA $\mathrm{Ab} \mathrm{L}$ chain in B cells is rather restricted to SLE patients with active renal involvements (8). In this paper, we have shown that receptor editing mechanism may be defective in patients with active renal disease and that A30 locus, encoding nephritogenic anti-DNA Ab L chain, has some defects in patients without nephritis, resulting in the absence of cationic anti $\mathrm{DNA} \mathrm{Ab}$ and renal manifestations.

Pargent et al. (10) have reported 16 polymorphisms in the human Ig k locus by comparing the restriction patterns of the DNA from 23 unrelated individuals. The human Ig $\mathrm{k}$ locus comprises two very similar but not identical copies on the short arm of chromosome 2 at 2p11-2p12: Ck proximal copy and distal copy (32). It is assumed that the duplicated $\mathrm{k}$ locus arises from an originally single copy locus by amplification processes similar to the evolution of the $\mathrm{W}$ region gene. $\mathrm{W}$ region $\mathrm{Vk}$ gene

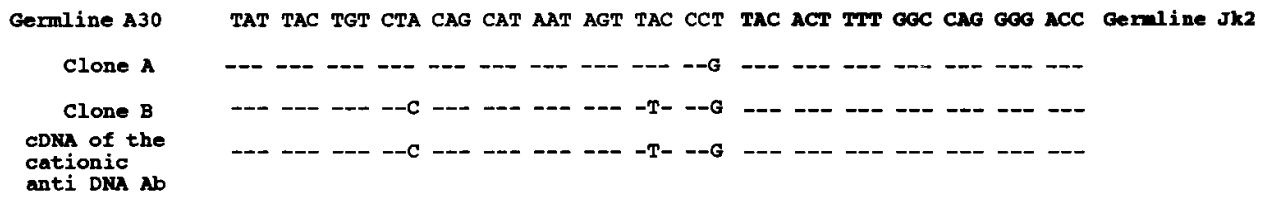

Figure 6. Characterization of the A30-Jk2 rearranged gene segment in normal B cells. Conventional $\mathrm{PCR}$ products of purified $\mathrm{B}$ cell genomic DNA using A30 primer and $\mathrm{Jk} 2$ primer $(\sim 300 \mathrm{bp})$ were recov-

ered, and nested PCR was carried out using gs87 primer and Jk2 primer. Resultant PCR fragments were directly sequenced. We sequenced nine clones (three clones each for three normal individuals). Among the nine clones sequenced, seven clones are the same with clone A, whereas the remaining two are the same with clone $\mathrm{B}$. 
cluster includes $11 \mathrm{Vk}$ genes and exists on the long arm of chromosome 2 at 2 cen-q11. Zimmer et al. (33) postulated that the W region cluster has been constructed primary transposition from the short to the long arm of chromosome 2 by a pericentric inversion, and then amplified in two subsequent steps. They suggested that the gene amplification or transposition might occur at the site homologous to the Alu or LINE sequence $(34,35)$. The $0.8-\mathrm{kb}$ upstream of A30 gene is a LINE homology region, HSBP65912, that has a breakpoint when compared with its duplicated copy (23). Thus, it is plausible to assume that the upstream of A30 gene, in which regulatory gene elements may exist, is prone to be altered during evolution.

Previous reports suggest that there is no major alteration in the structure or genomic organization of $\mathrm{Ig} \mathrm{L}$ chain genes in patients with SLE (17). Nonetheless, we found that A30 locus has some defects in patients without lupus nephritis and minority of normal individuals. The defects of A30 locus in patients with SLE may lead to the absence of the functional A30 germline gene, leading to the escape from developing lupus nephritis. It is interesting to postulate that as far as A30 locus, SLE patients without nephritis may belong to one subpopulation that differ from the subpopulation of SLE patients with nephritis in their genealogy. Thus the conventional PCR study we have conducted may give some insight into whether a patient develops lupus nephritis or not.

As the mechanisms for the development and maintenance of self-tolerance, clonal deletion $(36,37)$, clonal anergy $(38)$, and receptor editing $(28,29,39)$ of autoreactive $\mathrm{B}$ cells have been postulated. Clonal deletion ordinarily means apoptotic cell death of autoreactive lymphocytes. Nonetheless, clonal deletion may include receptor editing, a mechanism revising their surface Ig receptor by secondary gene rearrangement, and abnormal receptor editing may be one of the important mechanisms of defects in self-tolerance.

Bensimon et al. have reported the cDNA cloning of the $\mathrm{Vk}$ genes of a panel of human anti-DNA Ab derived from four patients with SLE (40), which are O-81 idiotype positive (41-43). In their study, all the Vk genes used map to the less than $280-\mathrm{kb}$ portion of the $3^{\prime}$ end of the Vk locus, suggesting that they represent essentially the products of primary rearrangement (40). This proximal clustering of the Vk genes used contrasts with the broad distribution of immunization-induced human $\mathrm{Ab}$ that used Vk genes spanning over 1,400 kb of the entire locus. In addition, lupus autoAbs show no tendency to express the downstream Jk exon; another indication of infrequent secondary variable gene assembly. Because successive rearrangements may extinguish high-affinity recognition of self-Ag, they proposed that this bias in $\mathrm{Vk}$ and $\mathrm{Jk}$ expression reflected a low rate of secondary $\mathrm{L}$ chain rearrangements among lupus auto $\mathrm{Ab}$. This is the case for the anti-DNA Ab we have studied; A30 gene that encodes cationic anti-DNA Ab locates the 250-kb portion of the $3^{\prime}$ end; in addition, in the cationic anti-DNA cDNA, A30 gene is rearranged with the upstream Jk, Jk2 gene (8). Genomic DNA of normal B cells contained edited A30$\mathrm{Jk} 2$ gene that is productively rearranged, whereas SLE B cells contained A30-Jk2-Ck gene (see Fig. 5) and express the mRNA (8). We favor that cationic anti-DNA Ab encoded by A $30-\mathrm{Jk} 2$ may be a primary gene rearrangement product due to the failure of receptor editing mechanism.

Receptor editing is believed to occur in the bone marrow at a pre-B to immature $B$ transitional stage of $B$ cell differentiation (39). Within the receptor editing theory, it has been postu- lated that emergence of autoreactive receptors in B cells results in expression of high levels of Ig-recombinases that will mediate secondary rearrangements on the accessible $\mathrm{L}$ chain $\mathrm{V}$ genes, evaluated from the experiments using murine transgene models $(28,29,37,39)$. It has been reported that the A30 gene is expressed as autoreactive Ig L chains such as an antiplatelet integrin IIb heavy chain Ab, HUMIGKVJ (unpublished data), and our anti-DNA autoAb (8). Our previous study revealed that cationic anti-DNA Ab L chain mRNA, was expressed only in the patients with active renal involvements, but not normal individuals and expression of the mRNA is restricted to autoreactive B cells of the patients (8). A30 gene is categorized as a functionally competent $\mathrm{Vk}$ gene by Zachau and co-workers, because there is no structural abnormality in the gene such as abnormalities in heptamer-nonamer sequences or a promoter region (22). We have confirmed Zachau's finding (Fig. 2). Nonetheless, A30 is rarely used in the functional Ig $\mathrm{Vk}$ gene repertoire (27). The reason for the extremely low frequency of the functionally competent A30 gene usage has been obscure. One possible explanation is that A30 gene is autoAbassociated germ line Vk gene, and in normal B cell development, such B cells would be edited by receptor editing mechanism. The precise role of the VL chain for anti-DNA Ab binding to the $\mathrm{Ag}$ is not clear. Nonetheless, the contribution of both $\mathrm{VH}$ and VL chains to DNA reactivity of some murine IgG Ab has been shown (44-47). We believe that VL chain is important for autoreactivity of the $\mathrm{Ab}$ and failure of receptor editing is intimately associated with the development of autoimmunity, especially at the beginning of autoimmune responses.

It is possible that anti-DNA Ab-producing B cells that have appeared in the peripheral lymphoid tissues, by failure of receptor editing at the immature/mature transitional stage of B cell maturation in the bone marrow, would be stimulated by DNA or cross-reactive Ag via Ag-specific manner, resulting in clonal expansion of the B cells and further acquisition of somatic mutations of their $\mathrm{Ig} \mathrm{V}$ gene. Several distinct mechanisms that permit survival and propagation of the autoreactive B cellssuch as failure of clonal deletion, failure of clonal anergy, Ag that specifically stimulates autoreactive B cells, and failure of receptor editing-would operate simultaneously to break self-tolerance, leading to the development of the auto $\mathrm{Ab}$ and the disease manifestation of SLE. In addition, repetitive stimulation of autoreactive B cells for a long time and hormonal influences may be necessary for the development of autoimmune diseases.

In summary, in addition to the somatic mutation that has already been emphasized for its importance, genetic predisposition including polymorphisms of Ig Vk locus, and failure of receptor editing may contribute to the pathogenic anti-DNA responses in humans.

\section{Acknowledgments}

This work was supported in part by 1993/1994 and 1995 grants-in-aid for scientific research, projects 04454238 and 07457128 from the Ministry of Education, Science and Culture of Japan, a 1994/1995 research grant from the Autoimmune Disease Research Committee of Japan, the Ministry of Welfare and Health of Japan.

\section{References}

1. Smith, H.R., and A.D. Steinberg. 1983. Autoimmunity: a perspective. Ann. Rev. Immunol. 1:175-210. 
2. Theofilopoulos, A.N., and F.J. Dixon. 1985. Murine models of systemic lupus erythematosus. Adv. Immunol. 37:269-390.

3. Tan, E.M. 1993. Auto-antibodies in systemic lupus erythematosus. In Arthritis and Allied Conditions: a Textbook of Rheumatology. 12th ed. D.J. McCarty and W.J. Koopman, editors. Lea \& Febiger, Philadelphia. 1179-1184.

4. Woods, V.L., Jr., and N.J. Zvaifler. 1989. Pathogenesis of systemic lupus erythematosus. In Textbook of Rheumatology. 3rd ed. W.N. Kelley, E.D. Harris, S. Ruddy Jr., and C.B. Sledse, editors. W.B. Saunders, Philadelphia. 10771100.

5. Ebling, F., and B.H. Hahn. 1980. Restricted subpopulations of DNA antibodies in kidneys of mice with systemic lupus: comparison of antibodies in serum and renal eluates. Arthritis Rheum. 23:392-403.

6. Suzuki, N.,T. Harada, Y. Mizushima, and T. Sakane. 1993. Possible pathogenic role of cationic anti-DNA autoantibodies in the development of nephritis in patients with systemic lupus erythematosus. J. Immunol. 151:11281136.

7. Suzuki, N., I. Otuka, T. Harada, Y. Mizushima, and T. Sakane. 1994. Preferential adsorption of cationic anti-DNA antibodies with immobilized polyanionic compounds, dextran sulfate. Autoimmunity. 19:105-112.

8. Harada, T., N. Suzuki, Y. Mizushima, and T. Sakane. 1994. Usage of a novel class of germline immunoglobulin variable region gene for cationic antiDNA autoantibodies in human lupus nephritis and its role for the development of the disease. J. Immunol. 153:4806-4815.

9. Malcolm, S., P. Barton, C. Murphy, M.A. Ferguson-Smith, D.L. Bentley, and T.H. Rabbitts. 1982. Localization of human immunoglobulin $\kappa$ light chain variable region genes to the short arm of chromosome 2 by in situ hybridization. Proc. Natl. Acad. Sci. USA. 79:4957-4961.

10. Pargent, W., K.F. Schable, and H.G. Zachau. 1991. Polymorphism and haplotypes in the human immunoglobulin $\kappa$ locus. Eur. J. Immunol. 21:18291835.

11. Meindl, A., H. Kellner, M. Schattenkirchner, and H.G. Zachau. 1990. Polymorphisms in the Vк gene patterns of rheumatoid arthritis patients and control individuals. Exp. Clin. Immunogenet. 7:20-25.

12. Moxley, G. 1992. Variable-constant segment genotype of immunoglobulin kappa is associated with increased risk for rheumatoid arthritis. Arthritis Rheum. 35:19-25.

13. Chen, P.P., K.A. Siminovitch, N.J. Olsen, R.A. Erger, and D.A. Carson. 1989. A highly informative probe for two polymorphic Vh gene regions that contain one or more autoantibody-associated Vh genes. J. Clin. Invest. 84:706710 .

14. Yang, P.M., N.J. Olsen, K.A. Siminovitch, T. Olee, F. Kozin, D.A. Carson, and P.P. Chen. 1990. Possible deletion of a developmentally regulated heavy-chain variable region gene in autoimmune diseases. Proc. Natl. Acad. Sci. USA. 87:7907-7911.

15. Olee, T., P.M. Yang, K.A. Siminovitch, N.J. Olsen, J. Hillson, J. Wu, F. Kozin, D.A. Carson, and P.P. Chen. 1991. Molecular basis of an autoantibodyassociated restriction fragment length polymorphism that confers susceptibility to autoimmune diseases. J. Clin. Invest. 88:193-203.

16. Shin, E.K., F. Matsuda, H. Nagaoka, Y. Fukita, T. Imai, K. Yokoyama, E. Soeda, and T. Honjo. 1991. Physical map of the $3^{\prime}$ region of the human immunoglobulin heavy chain locus: clustering of autoantibody-related variable segments in one haplotype. EMBO J. 10:3641-3645.

17. Zouali, M., M.P. Madaio, R.T. Canoso, and B.D. Stollar. 1982. Restriction fragment length polymorphism analysis of the $V_{\kappa}$ locus in human lupus. Eur. J. Immunol. 19:1759-1760.

18. Tan, E.M., A.S. Cohen, J.F. Fries, A.T. Masi, D.J. McShane, N.F. Rothfield, J.G. Schaller, N. Talal, and R.J. Winchester. 1982. The 1982 revised criteria for the classification of systemic lupus erythematosus. Arthritis Rheum. 25: 1271-1277.

19. Sambrook, J., E.F. Fritsch, and T. Maniatis. 1989. Molecular Cloning. 2nd ed. Cold Spring Harbor Laboratory Press, Cold Spring Harbor, NY. I47 pp.

20. Suzuki, N., T. Sakane, and E.G. Engleman. 1990. Anti-DNA antibody production by CD5 + and CD5- B cells of patients with systemic lupus erythematosus. J. Clin. Invest. 85:238-247.

21. Evans, G.A., and G.M. Wahl. 1987. Cosmid vectors for genomic walking and rapid restriction mapping. Methods Enzymol. 152:604-610.

22. Scott, M.G., D.L. Crimmins, D.W. McCourt, G. Chung, K.F. Schable, R. Thiebe, E.M. Quenzel, H.G. Zachau, and M. Nahm. 1991. Clonal characterization of the human IgG antibody repertoire to Haemophilis influenzae type b polysaccharide. IV. The less frequently expressed VL are heterogeneous. J. Immunol. 147:4007-4013.

23. Lautner-Rieske, A., C. Huber, A. Meindl, W. Pargent, K.F. Schable, R. Thiebe, I. Zocher, and H.G. Zachau, 1992. The human immunoglobulin $\kappa$ locus. Characterization of the duplicated A regions. Eur. J. Immunol. 22:1023-1029.
24. Barnes, W.M. 1994. PCR amplification of up to 35-kb DNA with high fidelity and high yield from $\lambda$ bacteriophage templates. Proc. Natl. Acad. Sci. USA. 91:2216-2220.

25. Cheng, S., S.Y. Chang, P. Gravitt, and R. Respess. 1994. Long PCR: as increasingly longer DNA targets are amplified reliably, new applications for PCR are becoming possible. Nature (Lond.). 369:684-685.

26. Mochizuki, M., N. Suzuki, M. Takeno, H. Nagafuchi, T. Harada, H. Kaneoka, N. Yamashita, K. Hirayama, T. Nakajima, Y. Mizushima, S. Yamamoto, and T. Sakane. 1994. Fine antigen specificity of human $\gamma \delta \mathrm{T}$ cell lines $(\mathrm{V} \gamma 9+)$ established by repetitive stimulation with a serotype (KTH-1) of a gram positive bacterium, Streptococcus sanguis. Eur. J. Immunol. 24:1536-1543.

27. Klein, R., R. Jaenichen, and H.G. Zachau, 1993. Expressed human immunoglobulin $\kappa$ genes and their hypermutation. Eur. J. Immunol. 23:3248-3271.

28. Gay, D., T. Saunders, S. Camper, and M. Weigert. 1993. Receptor editing: an approach by autoreactive B cells to escape tolerance. J. Exp. Med. 177: 999-1008.

29. Tiegs, S.L., D.M. Russell, and D. Nemazee. 1993. Receptor editing in elf-reactive bone marrow B cells. J. Exp. Med. 177:1009-1020.

30. Radic, M.Z., and M. Weigert. 1994. Genetic and structural evidence for antigen selection of anti-DNA antibodies. Ann. Rev. Immunol. 12:487-520.

31. Diamond, B., J.B. Katz, E. Paul, C. Aranow, D. Lustgarten, and M.D. Scharff. 1992. The role of somatic mutations in the pathogenic anti-DNA response. Ann. Rev. Immunol. 10:731-757.

32. Meindl, A., H.-G. Klobeck, R. Ohnheiser, and H.G. Zachau.1990. The Vk gene repertoire in the human germ line. Eur. J. Immunol. 20:1855-1863.

33. Zimmer, F.J., H. Hameister, H. Schek, and H.G. Zachau. 1990. Transposition of human immunoglobulin Vk genes within the same chromosome and the mechanism of their amplification. EMBO J. 9:1535-1542.

34. Kariya, Y., K. Kato, Y. Hayashizaki, S. Himeno, S. Tarui, and K. Matsubara. 1986. Expression of human gastrin gene in normal and gastrinoma tissues. Gene. 50:345-352.

35. Skowronski, J., T.G. Funning, and M.E. Singer. 1988. Unit length Line-1 transcripts in human teratocarcinoma cells. Mol. Cell. Biol. 8:1385-1397.

36. Nemazee, D.A., and K. Burki. 1989. Clonal deletion of B lymphocytes in a transgenic mouse bearing anti-MHC class I antibody genes. Nature (Lond.). 337:562-566.

37. Chen, C., Z. Nagy, M. Z. Radic, R. R. Hardy, D. Huszar, S. A. Camper, and M. Weigert. 1995. The site and stage of anti-DNA B-cell deletion. Nature (Lond.). 373:252-255.

38. Goodnow, C.C., J. Crosbie, S. Adelstein, T.B. Lavoie, S.J. Smith-Gill, R.A. Brink, H. Pritchard-Briscoe, J.S. Wotherspoon, R.H. Loblay, K. Raphael, R.J. Trent, and A. Basten. 1988. Altered immunoglobulin expression and functional silencing of self-reactive B lymphocytes in transgenic mice. Nature (Lond.). 334:676-682

39. Radic, M.Z., J. Erikson, S. Litwin, and M. Weigert. 1993. B lymphocytes may escape tolerance by revising their antigen receptors. J. Exp. Med. 177: $1165-1173$.

40. Bensimon, C., P. Chastanger, and M. Zouali. 1994. Human lupus antiDNA autoantibodies undergo essentially primary $\mathrm{V}_{\kappa}$ gene rearrangements. EMBO J. 13:2951-2962

41. Muryoi, T., T. Sasaki, A. Hatakeyama, S. Shibata, M. Susuki, J. Seino, and K. Yoshinaga. 1990. Clonotypes of anti-DNA antibodies expressing specific idiotypes in immune complexes of patients with active lupus nephritis. $J$. Immunol. 144:3856-3861.

42. Chastagner, P., C. Demaison, J. Theze, and M. Zouali. 1994. Clonotypic dominance and variable gene elements of pathogenic anti-DNA autoantibodies from a single patient with lupus. Scand. J. Immunol. 39:165-178.

43. Demaison, C., P. Chastanger, J. Theze, and M. Zouali. 1994. Somatic diversification in the heavy chain variable region genes expressed by human autoantibodies bearing a lupus-associated nephritogenic anti-DNA idiotype. Proc. Natl. Acad. Sci. USA. 91:514-518.

44. Radic, M.Z., M.A. Mascelli, J. Erikson, H. Shan, and M. Weigert. 1991. $\mathrm{IgH}$ and $\mathrm{L}$ chain contributions to autoimmune specificities. J. Immunol. 146 : $176-182$.

45. Jang, Y.J., and B.D. Stollar. 1990. Ultraviolet cross-linking of helical oligonucleotides to two monoclonal MRL-lpr/lpr anti-DNA autoantibodies: variation in $\mathrm{H}$ and L chain binding to DNA. J. Immunol. 145:3353-3359.

46. Mahmoudi, M., G.A. Denomme, J.Y. Edwards, D.A. Bell, and E. Cairns. 1995. The role of the immunoglobulin heavy chain in human anti-DNA antibody binding specificity. Arthritis Rheum. 38:389-395.

47. Erickson, J., M.Z. Radic, S.A. Camper, R.R. Hardy, C. Carmack, and M. Weigert. 1991. Expression of anti-DNA immunoglobulin transgenes in nonautoimmune mice. Nature (Lond.). 349:331-334. 